\title{
Effect of Injection Location and Multi-Hole Nozzle on Mixing Performance in a CNG-Fuelled Engine with Port Gas Injection, Using CFD Analyses
}

\author{
Tianbo Wang and Siqin Chang \\ School of Mechanical Engineering, Nanjing University of Science and Technology, Nanjing 210094, China
}

\begin{abstract}
A compressed natural gas injection device with moving-coil electromagnetic linear actuator and mushroom type poppet valve was designed to supply a large-bore intake port injection type engine with sufficient fuel timely. The transient engine CFD model combined with the poppet valve's motion was established to research the effect of injection conditions on the mixing homogeneity in the intake port and cylinder. Computed penetration distances of impinging jet with different $\mathrm{k}-\varepsilon$ models and different wall functions are compared with measured results in the literature to validate the model. It was observed that the gas injection location and number of nozzle holes have a significant effect on mixing performance both in the intake port and cylinder.
\end{abstract}

\section{Introduction}

Compressed natural gas $(\mathrm{CNG})$, one of the most promising alternative fuels, is widely used in engines due to its rich resource and cheap price [1]. Although the direct injection technology has been adopted to some gas fuel engine models [2], the multi-point port fuel injection (PFI) is still an important developing direction $[3,4]$.

The gas injection device (GID) is the ultimate component of engine fuel supply system, whose controllability and injection characteristics have a great influence on the engine performance. Currently the driver of GID is mostly solenoid, and the executing component is mostly in the form of spherical or needle valve [4]. Such kind of GIDs are small and can be installed in the engine conveniently, however, its mass flow rate is quite low. More importantly, its control accuracy, working reliability will be seriously dropped by the solenoid [5]. On the contrary, the moving-coil electromagnetic linear actuator has higher power density and better controllability, so it can be used as the driver of GID [6]. The mushroom type poppet valve can be used to deliver gas fuel to the large-bore engine because they have better sealing performance and higher mass flow rate.

The turbulent mixing in the port and inside the engine cylinder is a crucial issue for the investigation of the performance of a spark-ignition engine. The fuel-air mixture from liquid fuel is largely dependent on atomization and evaporation of the injected fuel droplets, while gaseous injection does not involve the complex phenomena. Mixing of gaseous fuel with ambient air is usually slower than that of liquid fuel due to the lower mass and momentum [7].

The CNG injection process in engine is similar to the transverse flow in the scramjet engine. Using flow visualization techniques, Fric and Roshko [8] found four different types of vortices between the jet and the cross-flow. They are the following: (i) the jet shear-layer vortices; (ii) the system of horseshoe vortices; (iii) the counter-rotating vortex pair (CVP); and (iv) the wake vortices.

The wall impingement jet is also involved with injection process both of liquid and gas fuel. The effect of cross-flow on gasoline spray impingement with port fuel injection was studied to conclude that the cross-flow decreases the axial velocity of impinging droplets [9]. The wall impingement effect on mixture preparation in a direct injection hydrogen-fuelled engine was studied using CFD and high-speed schlieren imaging technique [10].

The injection timing, location and number of nozzle holes of the GID have a significant impact on the in-cylinder mixture formation. Yamato, et al. [11] used CFD calculation and PIV measurement to see the effect of injection position on in-cylinder fuel distribution with an experiment engine. Scarcelli, et al. [12] used the commercial code Fluent to study the influence of singleand multi-hole nozzles on mixture preparation in a direct injection hydrogen-fuelled engine. However, all of the above studies must set the flow pattern and outlet mass flow before CFD simulation because they did not take into consideration of the internal structure of GID, which will affect the accuracy of simulation seriously.

In the present study, the GID using moving-coil electromagnetic linear actuator and mushroom type poppet valve is designed. Detailed computational fluid dynamics (CFD) simulations combined with the poppet valve's motion have been performed to analyse the effect of injection location and number of nozzle holes on the mixing performance in the intake port and cylinder. The 
cross-flow and wall impingement within intake port are emphasized.

\section{Working principle and structure of the injection device}

The moving-coil electromagnetic linear actuator, with higher power density and better controllability than the solenoid, is taken as driver of GID. Figure 1 shows the structure and prototype of GID. The driver consists of a moving coil, permanent magnets, an inner core, and an outer core. When the coil is energized, the Lorentz force produced in the coil actuates the valve to move. The electromagnetic force can be bidirectional as the direction of the current changes [6].

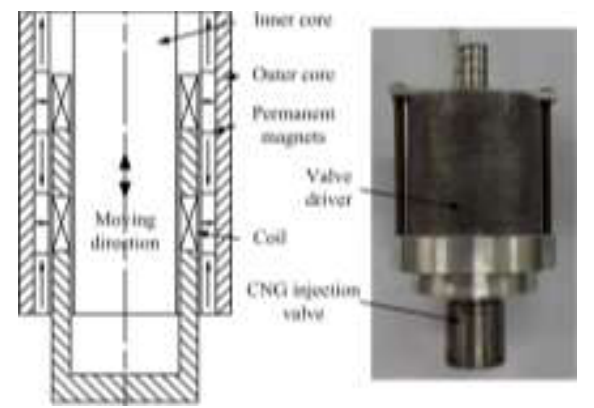

Figure 1. Structure and prototype of GID.

The large-bore CNG engine operating conditions and main dimensions of GID are listed in Table 1 and Table 2 respectively. The engine is fixed at 1900rpm in this study. According to the theoretical fuel consumption given in Equation(1)-(3), the steady CFD model keeping GID at maximum lift was established to validate that the GID can supply enough fuel to the engine at any operating condition within $7.89 \mathrm{~ms}$ corresponding to 90 crank angle (CA) at $1900 \mathrm{rpm}$.

Table 1. Specifications of engine.

\begin{tabular}{|c|c|}
\hline Parameter & Value \\
\hline Bore $(\mathrm{mm}) \times$ Stroke $(\mathrm{mm})$ & $131 \times 155$ \\
\hline Displacement volume $(\mathrm{L})$ & 12.53 \\
\hline Compression ratio & 11.5 \\
\hline Rated power(kW)/speed(rpm) & $255 / 1900$ \\
\hline $\mathrm{IVO} / \mathrm{IVC}(\mathrm{CA})$ & $30^{\circ} \mathrm{BTDC} / 46^{\circ} \mathrm{ABDC}$ \\
\hline $\mathrm{EVO} / \mathrm{EVC}(\mathrm{CA})$ & $78^{\circ} \mathrm{BBDC} / 30^{\circ} \mathrm{ATDC}$ \\
\hline
\end{tabular}

Table 2. Specification of gas injection device.

\begin{tabular}{|c|c|}
\hline Injection device parameter & Value \\
\hline Outlet diameter(mm) & 7 \\
\hline Valve lift(mm) & 1 \\
\hline Injection pressure(MPa) & 0.7 \\
\hline Transition time(ms) & 1.5 \\
\hline Injection duration $(\mathrm{ms})$ & 7.89 \\
\hline
\end{tabular}

Under a certain engine operating condition with output power $P_{e}$, the fuel consumption is given in Equation (1).

$$
m_{g}=P_{e} \cdot \rho / \eta_{\mathrm{e}} h_{\mu}
$$

And the fuel needed per cycle is given in Equation (2).

$$
m_{c y l .}=120 m_{\mathrm{g}} / n_{e}
$$

Eventually the steady mass flow of the injection device is calculated as given in Equation (3).

$$
m_{G}=720 m_{g} /\left(\phi_{\mathrm{g}}-6 n_{\mathrm{e}} \Delta t\right)
$$

where $P_{e}$, is the engine power; $\eta_{e}$, is the engine efficiency; $h_{\mu}$, is the low heating value of gas fuel; $\rho$, is the density; $n_{e}$, is the engine speed; $\Phi_{g}$, is the injection duration in $\mathrm{CA} ; \Delta t$, is the transition time of the driver.

\section{Numerical model and validation}

\subsection{Turbulence model validation}

An impinging jet can be divided into three regions: the free jet region, the impingement region and the wall jet region. Earlier numerical studies [13] have found some difficulties to correctly simulate simple impinging jets with standard $\mathrm{k}-\varepsilon$ turbulent model.

This study follows a RANS approach combined with a $\mathrm{k}-\varepsilon$ model to describe in-cylinder turbulence. The quality of the RANS results is not comparable to more detailed approach such as LES or DNS. However, the latter are not computationally affordable yet for engine applications. Turbulence is modelled using a standard $\mathrm{k}-\varepsilon$ model, a RNG k- $\varepsilon$ model and a realizable k- $\varepsilon$ model. Standard wall functions and non-equilibrium wall functions are used to model momentum and heat fluxes at the walls respectively.

Experimental measurements made by Fujimoto et al. [14] show motion and air-entrainment characteristics of round impinging gas jets. The measurements were obtained by injecting acetylene gas, $\mathrm{C}_{2} \mathrm{H}_{2}$, through a nozzle of $0.16 \mathrm{~cm}$ diameter into air where the pressure was $101.3 \mathrm{kPa}$ and the temperature was $293 \mathrm{~K}$. The injection duration was $26 \mathrm{~ms}$ with a mean injection pressure of $2.9 \mathrm{kPa}$. The nozzle orifice placed at $1.5 \mathrm{~cm}$ above the wall, at $\mathrm{L} / \mathrm{D}$ ratios of 9.4 is picked here to validate the turbulence model. The highest resolution in the radial direction is near the axis. A uniform grid size of $0.025 \mathrm{~cm}$ is used in the axial direction. For the free jet computations, the chamber height is $150 \mathrm{~mm}$.

The diffusion characteristic of wall-impinging jet is mostly indicated by the penetration distance. In this paper, the penetration of the transient wall-impinging jet after impingement is defined as the summation of the impinging distance, $\mathrm{L}$, and the radial distance, $\mathrm{X}$, to which the jet has penetrated along the wall. The computed penetration for impinging jets is defined as the impinging distance plus the maximum radial distance where the fuel mass fraction reaches a cut-off value of 0.01 [13].

As shown in Figure 2(a)(b), compared to the standard $\mathrm{k}-\varepsilon$ model and realizable $\mathrm{k}-\varepsilon$ model, the RNG model has been shown to be in better agreement with experiments in predicting gaseous jet penetration history for free jet and wall-impinging jet. And it can be seen from Figure 2(c) that non-equilibrium wall functions seem to be more precise than standard wall functions. 


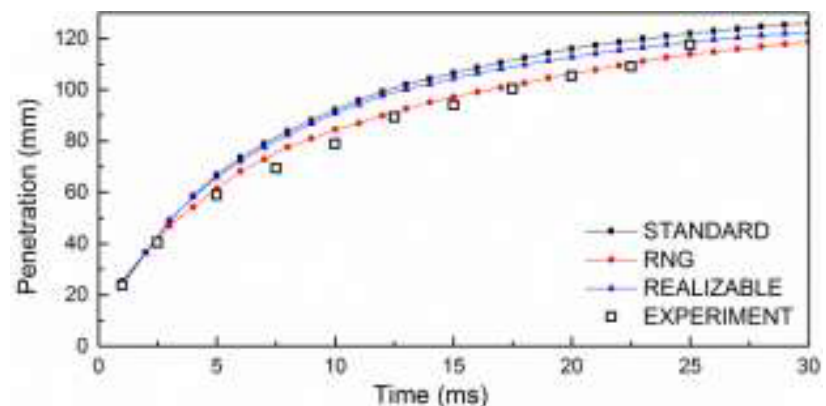

(a) Turbulence model's effect on the penetration of free jet

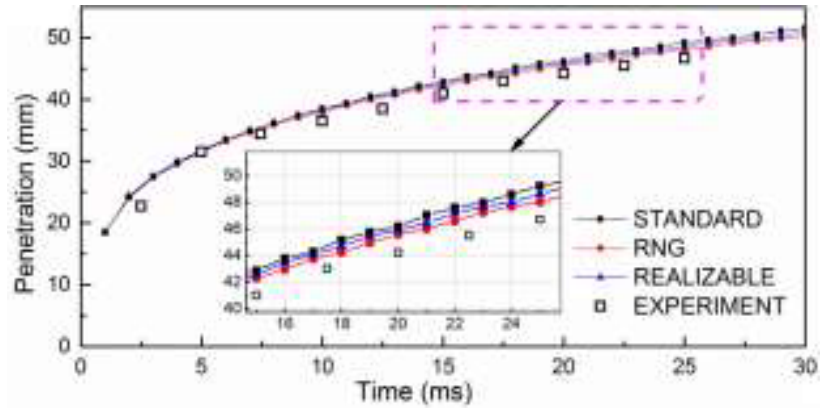

(b) Turbulence model's effect on the penetration of wall jet

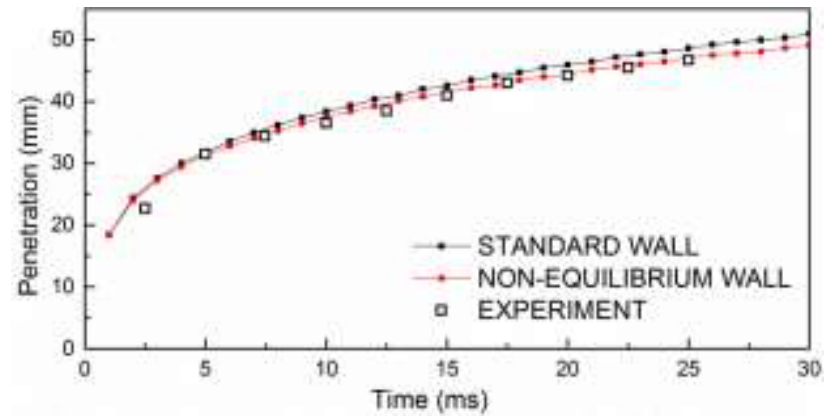

(c) Comparison of penetration using different wall functions

Figure 2. Comparison of penetration with Fujimoto's experiments.

\subsection{Grid independence study}

One of the most important variables affecting the numerical model ability to predict the flow correctly is the number of grid points across the GID exit. Due to the complexity of GID geometry, it is initially necessary to fix the poppet valve position during the computations, instead of implementing the valve lift with time. And to exclude the influence of intake port wall on the gas jet pattern, the jet export zone was set as a cylinder-shaped chamber with diameter of $70 \mathrm{~mm}$, height of $150 \mathrm{~mm}$.

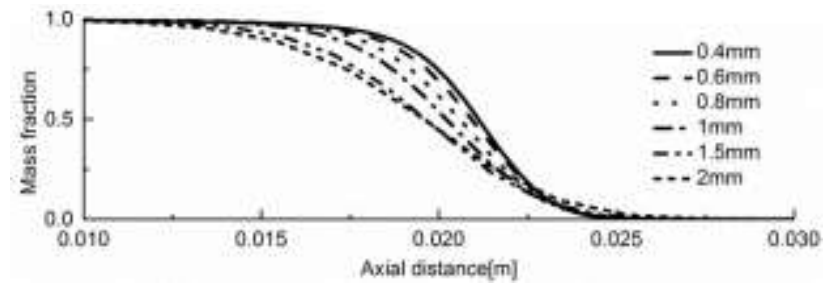

Figure 3. The results of grid independency check.

The results for mass fraction distribution along the exit axis of the cylinder-shaped chamber at time $0.1 \mathrm{~ms}$ after injection start have been plotted against size of grid cells across the exit in Figure 3. It could be seen that mass fraction tends to be stable with decrease in size of grid cells. But decreasing the size of grid cells to smaller than $1 \mathrm{~mm}$ seems to have little effect on the mass fraction. This suggests $1 \mathrm{~mm}$ of the grid cells size is appropriate for grid-independent numerical simulation of CNG injection.

\subsection{Case studies}

As mentioned in the earlier section, injection location and number of nozzle holes are considered in the case studies. Different cases according to injection location and number of nozzle holes are shown in Figure 4. For case1 the GID is installed on the up side of the intake port, perpendicular to the axis of intake port. Based on case1, one short tube, with the same diameter of the GID outlet, was added to the outlet nozzle for case2. The length of the tube is $30 \mathrm{~mm}$. Case 2 shortens the impinging distance L with respective to case1. Case 3 has 5 holes of the same diameter, and the total cross area of these 5 holes is the same as case1. At last, the gas jet is oriented to the helical intake and tangential intake port separately for case 4 and case 5. It should be noted that all the above cases are compared by keeping all the other parameters, such as injection timing, injection duration, engine speed and load, identical

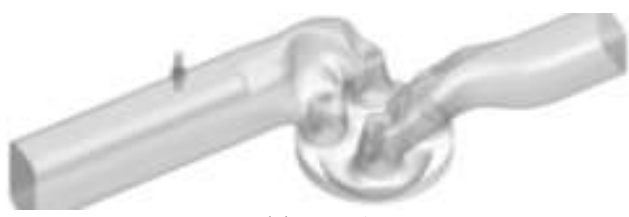

(a) case 1

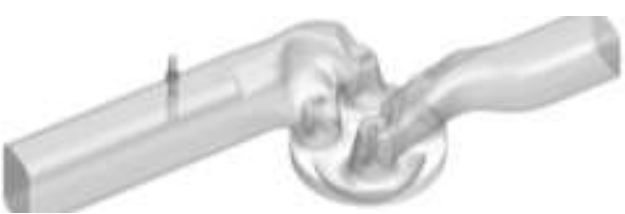

(b) case 2

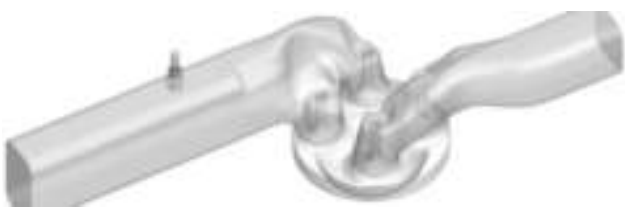

(c) case3

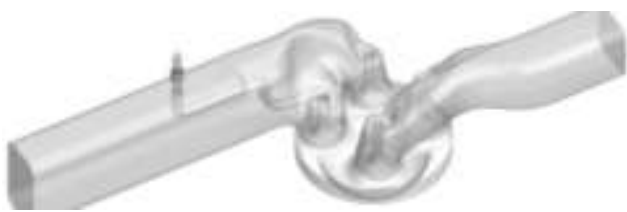

(d) case 4

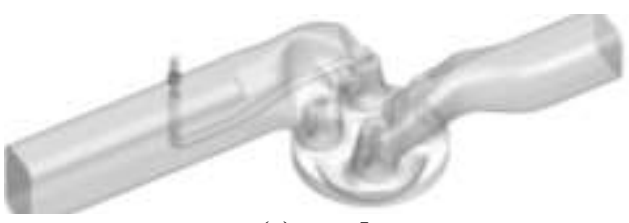

(e) case 5

Figure 4. Case studies. 


\subsection{Meshing and boundary conditions}

According to the results of the grid independence study, for single-hole (case 1, 2, 4, 5), the grid near GID outlet is shown in figure 5(a), and for 5-hole (case3), the grid is shown in figure 5(b). The valve regions (near the poppet valve and engine valve) involve finer discretization, and the other regions are discretized with coarser grid.

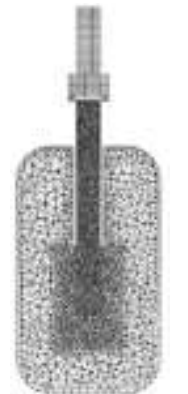

(a) single-hole

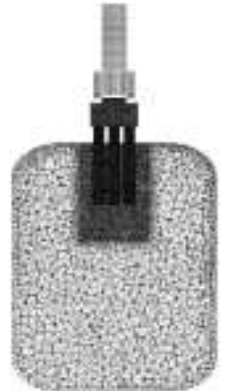

(b)multi-hole
Figure 5. Computational grids.

The intake boundary condition of engine is set as $2 \mathrm{bar}$ (turbo-charged), $353 \mathrm{~K}$, and the exhaust condition is set as $1.8 \mathrm{bar}, 773 \mathrm{~K}$. The whole domain is assumed to be initially quiescent. Calculation starts at $30^{\circ} \mathrm{BTDC}$ when the intake valve opening (IVO). The RNG k- $\varepsilon$ turbulence model with non-equilibrium wall functions is used for closure. The program is based on the pressure-correction method and uses the PISO algorithm. The first order upwind differencing scheme is used for the momentum, energy and turbulence equations. The run time for each case is typically about 70 hours on Intel core 17 computer.

\section{Results and discussion}

The gas fuel mass fraction contour of seven isometric cross sections after the installation location of GID and iso-surface under these conditions are shown in figure 6. The comparisons are carried out at CA430 when GID begins to close. The iso-surface value level in the intake port is 0.2 , and the in-cylinder value level is 0.08 .

It can be observed that the CVP dominates the mixing process in the port for case1 and fuel mass fraction contour on every cross section has a heart shaped distribution. The gas fuel gets into cylinder through both the helical and tangential intake port, and then impacts on the piston. After the impact, the flow direction is changed to along with the groove at the top of piston. The mixing performance in intake port for case 2 is quite similar to that of case1, except that the regular heart shaped distribution of mass fraction is broken by the down side wall of the intake port. For case 3 with 5 nozzle holes, two fuel jets are compelled to the up side of the intake port, while the other three jets still take the form of CVP under the effect of air flow. The in-cylinder iso-surface for case 1 , case 2 and case 3 is quite analogical with each other. For case4, the gas jet will flow to the cylinder centre under the guide of intake valve in helical port, and impinge on the cylinder wall and piston top. On the other side, for case 5, the gas jet will flow along the cylinder wall under the guide of intake valve in tangential port.

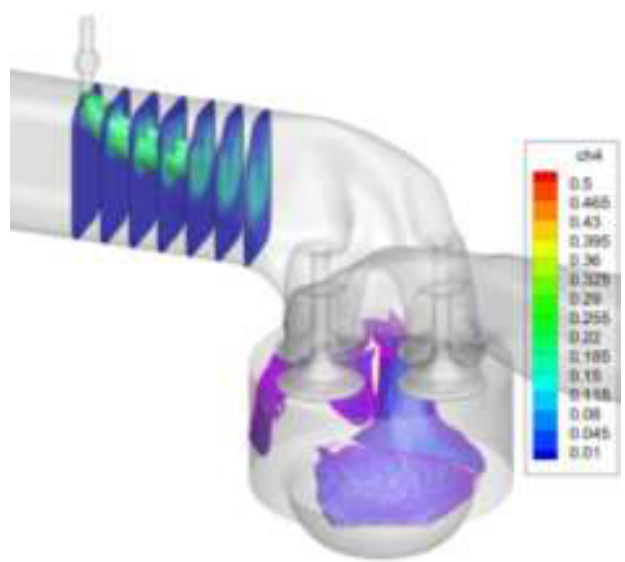

(a) case 1

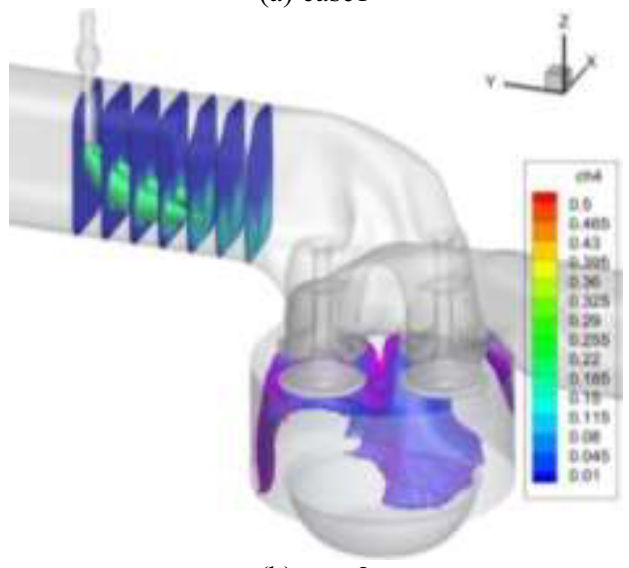

(b) case 2

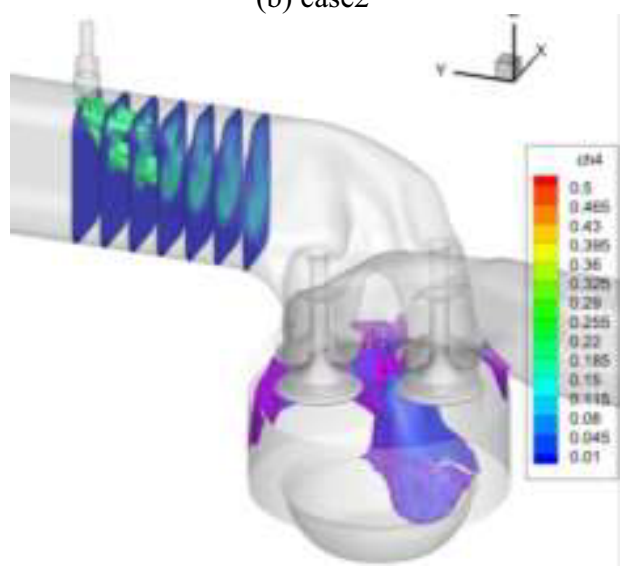

(c) case3

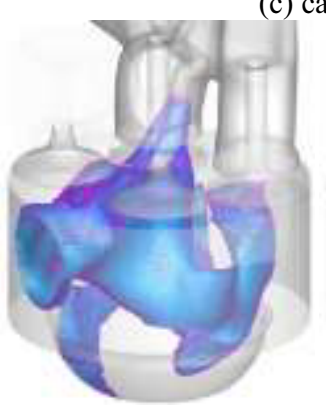

(d) case4

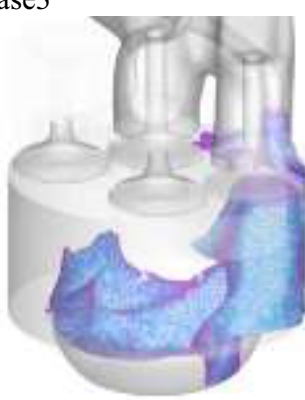

(e) case 5
Figure 6. The fuel mass fraction contour and iso-surface at CA430.

In order to analyse the mixing degree in the intake port of case1-3, the standard deviation of fuel mass fraction in the cross section $100 \mathrm{~mm}$ downstream installation position is plotted in figure 7 because the 
mixture formation of all these cross sections are quite similar to each other as shown in Figure 6. General speaking, the standard deviation for case 2 is larger than case 1 and case 3 during the injection process (CA340-CA447), that is, the mixing performance is worse. On the contrary, the standard deviation for case 3 is smaller. The plane vertical to the axis of cylinder, near the spark plug ( $3 \mathrm{~mm}$ apart from the cylinder top) is taken to discuss in-cylinder mixing performance. The standard deviation of the in-cylinder cross section is also plotted in Figure 7. It is obvious that the mixing performance of intake port agrees with that of cylinder.

However, the effect of different injection conditions on in-cylinder standard deviation will be weakened when the intake valve is closed. It is meaningless to use standard deviation as evaluation criterion at firing TDC because the standard deviation is less than 0.003 for all cases by this time. So the probability distribution frequency (PDF) of different mass fraction domains is compared further.

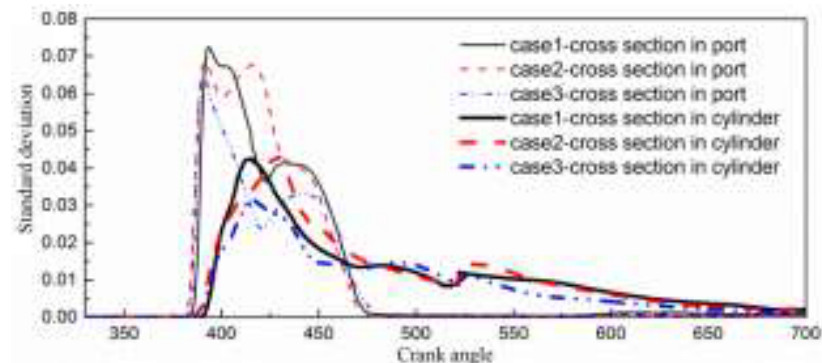

Figure 7. Comparison of mixing performance in intake port and cylinder for case1-3.

The cylinder zone is divided into eight parts according to in-cylinder fuel mass fraction, from lean to rich: $0-0.01$, 0.01-0.015, 0.015-0.02, $0.02-0.025, \quad 0.025-0.03$, $0.03-0.035,0.035-0.04,0.04-0.045$. The PDF of these parts are shown in Figure 8. According to total in-cylinder air and fuel mass when the intake valve is closed, the mean fuel mass fraction is in the region of $0.025-0.03$ for case 1-2, and 0.02-0.025 for case 3-5. These two regions are defined as the best mixture concentration region (BMCR) for corresponding injection conditions. It can be assumed that with the larger of PDF in the BMCR the better is in-cylinder mixing performance.

For case 2 the PDF of the BMCR is smaller, and there is more lean and rich mixture in cylinder at sparking time than for case1. So it can be concluded that the mixing performance both in intake port and cylinder would be worse if the impinging distance $\mathrm{L}$ is shortened. The PDF of the BMCR at the sparking time is about $73.7 \%$ for case 3 , while this value for case 1 is about $63.3 \%$. What's more, for case 3 there is almost no mixture in the concentration region of $0.03-0.045$ and $0-0.02$ at TDC. The multi-hole nozzle is beneficial for improving the mixing degree both in intake port and cylinder. For case4, the PDF of the BMCR is $90.2 \%$, larger than other cases. This can be regarded as complete mixing. On the contrary, for case5, because the fuel jet flows along the cylinder wall, the PDF of each concentration region changes very little and the PDF of the BMCR at sparking time is about $41.5 \%$, which is the worst compared with the other cases.
The mixing performance will be improved if the gas fuel is oriented to the helical port alone, while the mixing performance will be weakened greatly if fuel is oriented to the tangential port alone.

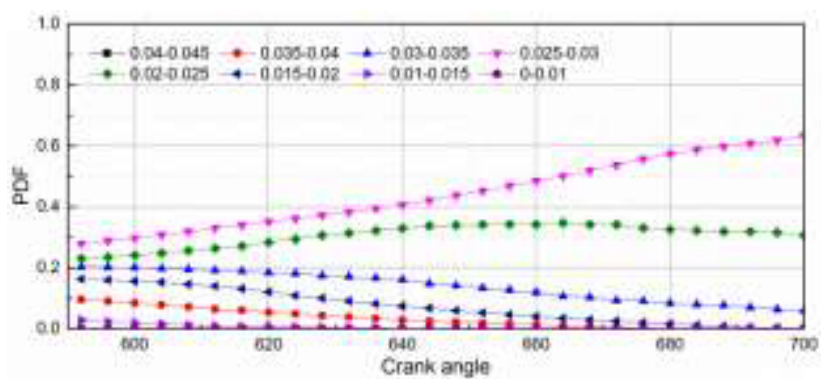

(a) case 1

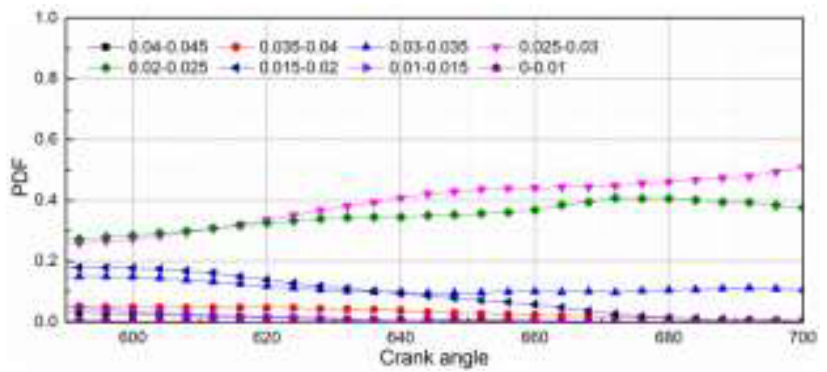

(b) case 2

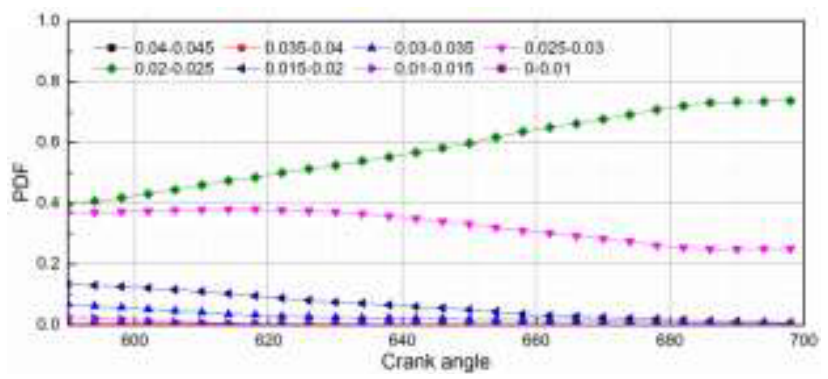

(c) case 3

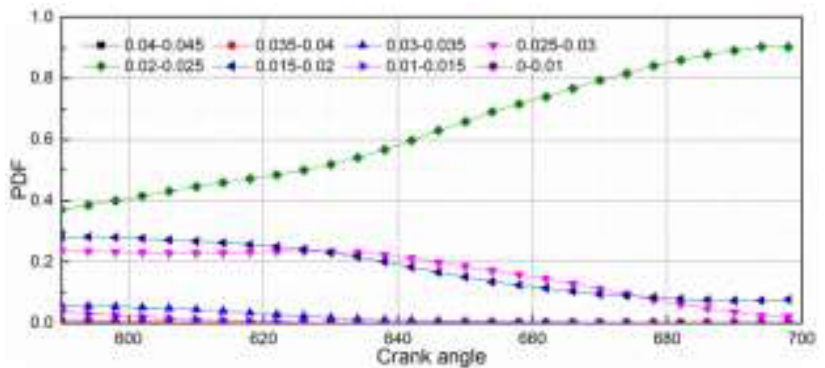

(d) case 4

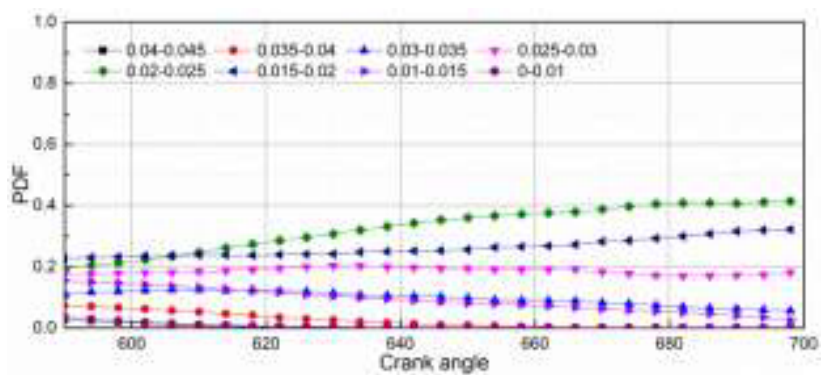

(e) case 5

Figure 8. PDF of all mass fraction regions for different injection conditions. 


\section{Conclusion}

The main conclusions are drawn as given below:

1) The GID using the moving-coil electromagnetic linear actuator and mushroom type poppet valve was projected.

2) The RNG $k-\varepsilon$ model and non-equilibrium wall functions are more accurate in predicting the gas jet. Different $k-\varepsilon$ models are employed to represent turbulence, and two kinds of wall functions are employed to model momentum fluxes at the walls. The computed penetration distances of free jet and impinging jet are compared with measured results in the literature.

3) The mixing performance both in intake port and cylinder would be worse if the impinging distance $\mathrm{L}$ is shortened.

4) Number of nozzle holes has a significant effect on the mixture formation in the port. The multi-hole nozzle is beneficial for improving the mixing performance both in intake port and cylinder.

5) The mixing performance will be improved if the gas fuel is oriented to the helical port alone, while the mixing performance will be weakened greatly if fuel is oriented to the tangential port alone.

6) Injection location and number of nozzle holes do not seem to have an obvious effect on the in-cylinder gas movement intensity.

\section{Acknowledgement}

This work was supported by the National Natural Science Foundation of China [grant number 51306090]; and the Natural Science Foundation of Jiangsu Province, China [grant number BK20130762].

\section{References}

1. Y. K. Gebre-Mariam, Testing for unit roots, causality, cointegration, and efficiency: The case of the northwest US natural gas market, Energy 36,5, 3489-3500(2011).

2. M. H. Li, Q. Zhang, G. X. Li, and S. D. Shao, Experimental investigation on performance and heat release analysis of a pilot ignited direct injection natural gas engine, Energy 1,10(2015).
3. M. A. Soberanis Escalante and A. M. Fernandez, A review on the technical adaptations for internal combustion engines to operate with gas/hydrogen mixtures, Int. J. Hydrogen Energy 35, 21, 12134-12140(2010).

4. R. Bircann, Y. Kazour, K. Dauer, M. Fujita, A. Wells, D. F. Kabasin, and H. Husted, Cold performance challenges with cng pfi injectors, SAE Paper No.2013-01-0863(2013).

5. H. Glasmachers, J. Melbert, and A. Koch, Sensorless movement control of solenoid fuel injectors, SAE Paper No.2006-01-0407(2006).

6. L. Liu, and S. Q. Chang, Motion control of an electromagnetic valve actuator based on the inverse system method, Proc. IMechE Part D:J. Automobile Engineering, 226,1, 85-93(2011).

7. J. Abraham, V. Magi, J. Maclnnes, and F. V. Bracco, Gas versus spray injection: which mixes faster, SAE Paper No.940895(1995).

8. T. Fric, and A. Roshko, Vortical structure in the wake of a transverse jet, J. Fluid Mech, 279, 1-47(1994).

9. M. R. Panao, A. L. N. Moreira, and D. F. G. Durao, Effect of a cross-flow on spray impingement with port fuel injection systems for HCCI engines, Fuel 106, 249-257(2013).

10. R. Scarcelli, T. Wallner, N. Matthias, V. Salazar, and S. Kaiser, Numerical and optical evolution of gaseous jets in direct injection hydrogen engines, SAE paper no. 2011-01-0675(2011).

11. T. Yamato, H. Sekino, T. Ninomiya and $M$. Hayashida, Stratification of in-cylinder mixture distributions by tuned port injection in a 4-valve SI gas engine, SAE Paper No.2001-01-0610(2001).

12. R. Scarcelli, T. Wallner, N. Matthias, V. Salazar, and S. Kaiser, Mixture formation in direct injection hydrogen engines: CFD and optical analysis of single- and multi-hole nozzles, SAE paper no. 2011-24-0096(2011).

13. S. M. Hosseinalipour and A. S. Mujumdar, Comparative evaluation of different turbulence models for confined impinging and opposing jet flows, Numer. Heat Transf., 28,6,647-666(1995).

14. H. Fujimoto, G.-S. Hyun, M. Nogami, K. Hirakawa, T. Asai, and J. Senda, Characteristics of free and impinging gas jets by means of image processing, SAE paper no. 970045(1997). 